\title{
Enhancement of in Vivo Anti-influenza Virus Activity of 5,7,4'-Trihydroxy-8-methoxyflavone by Drug Delivery System Using Hydroxypropyl Cellulose
}

\author{
Takayuki Nagal, ${ }^{a}$ Yoshihisa Nishibe, ${ }^{b}$ Yuji Makino, ${ }^{b}$ Tsuyoshi Tomimori,${ }^{c}$ and \\ Haruki YAMADA*,a \\ Oriental Medicine Research Center, The Kitasato Institute, ${ }^{a}$ 5-9-1 Shirokane, Minato-ku, Tokyo 108, Japan, \\ Pharmaceutical Products Research Laboratories, Teijin Limited, ${ }^{b}$ 4-3-2 Asahigaoka, Hino-shi, Tokyo 191, Japan and \\ School of Pharmacy, Hokuriku University, ${ }^{c}$ Ho-3 Kanagawa-machi, Kanazawa-shi, Ishikawa 920-11, Japan. \\ Received February 24, 1997; accepted July 2, 1997
}

\begin{abstract}
Enhancement of in vivo antiviral activity of 5,7,4'-trihydroxy-8-methoxyflavone (F36) against H3N2 subtype of influenza A virus by drug delivery system (DDS) with hydroxypropyl cellulose (HPC) was studied.

Although in the absence of HPC F36 $(0.5 \mathrm{mg} / \mathrm{kg})$ showed no antiviral activity against mouse-adapted influenza virus $\mathrm{A} /$ Guizhou/54/89 (H3N2) in mice, when F36 solution containing HPC was administered intranasally 5 min after the virus inoculation, proliferation of the virus in both nasal and broncho-alveolar cavities was inhibited significantly.

The relationship between concentration $(0.2-0.5 \%)$ and deposition ratio of HPC was studied. When $10 \mu \mathrm{l}$ of fluorescein isothiocyanate (FITC)-conjugated HPC solution was administered intranasally to BALB/c mice, deposition ratio of $\mathrm{HPC}$ at $6 \mathrm{~h}$ after inoculation in nasal cavity was dependent on its concentration. The deposition ratio of HPC in broncho-alveolar cavity, however, was reversely dependent on its concentration.

Anti-influenza virus activity of $\mathrm{F36}$ in nasal and broncho-alveolar cavities was dependent both on the concentration and deposition ratio of HPC. HPC was most effective at $0.5 \%$ in nasal cavity and at $0.3 \%$ in broncho-alveolar cavity. These results indicate that DDS with HPC enhances the anti-influenza virus activity of F36 in vivo.
\end{abstract}

Key words flavone; influenza virus; hydroxypropyl cellulose; drug delivery system

Influenza virus sialidase is believed to relate to the viral infection. ${ }^{1,2)}$ Therefore, influenza virus sialidase inhibitors can possibly inhibit the virus infection. We screened influenza virus sialidase specific inhibitor from plant flavonoids and found 5,7,4'-trihydroxy-8-methoxyflavone (F36) from the roots of Scutellaria baicalensis to be a potent inhibitor ${ }^{3)}$ F36 inhibited the replication of influenza virus A/PR/8/34 (H1N1 subtype) not only in Madin-Darby canine kidney (MDCK) cells, ${ }^{3)}$ but also in mouse lung by intranasal and intraperitoneal administration. ${ }^{4)}$ Intranasal administration of $\mathrm{F} 36$ protected mice against a lethal $\mathrm{A} /$ PR 8 virus infection. ${ }^{4}$ Studies on the mode of action suggested that F36 showed the anti-A/PR8 virus activity by inhibiting the fusion of the virus with endosome/lysosome membrane and budding from the MDCK cell surface. ${ }^{5)}$

We also tested the effects of F36 on infections of influenza $A$ virus, $\mathrm{H} 3 \mathrm{~N} 2$ subtype, and influenza $B$ virus in mice. When F36 was administered intranasally only 5 min before the infection, the lung virus titer was not reduced for either A/Guizhou virus, H3N2 subtype, or B/Ibaraki virus, although H1N1 subtype of influenza A virus was reduced under the same condition. When the same administration was done 7 times from $18 \mathrm{~h}$ before to $54 \mathrm{~h}$ after virus infection, however, F36 reduced the proliferation of both $\mathrm{A} /$ Guizhou and $\mathrm{B} / \mathrm{Ibaraki}$ viruses in the lung, although the reducing activity was still not potent. ${ }^{6}{ }^{6}$

Hydroxypropyl cellulose (HPC) is a mucoadhesive polymer and has been used in nasal preparations to maintain higher local concentration of a drug. ${ }^{7)}$ In the present paper, a drug delivery system (DDS) with HPC was studied to enhance the antiviral activity of F36 against H3N2 subtype of influenza A virus in vivo.

* To whom correspondence should be addressed.

\section{MATERIALS AND METHODS}

Materials F36 was purified from the root of S. baicalensis $^{8)}$ or synthesized according to previously described procedures. ${ }^{9}{ }^{90}$ ) Sodium $p$-nitrophenyl- $N$-acetyl- $\alpha$-D-neuraminate (PNP-NeuAc) was purchased from Wako Pure Chemical Industries, Ltd. (Osaka, Japan). HPC-H was obtained from Nippon Soda Co., Ltd. (Tokyo, Japan). Fluorescein isothiocyanate (FITC)-labeled HPC was prepared by the method of Kinoshita et al. ${ }^{11)}$

Cells and Viruses MDCK cells were grown in Eagle's minimum essential medium (EMEM) containing 10\% heat-inactivated fetal bovine serum, penicillin G (100 units $/ \mathrm{ml})$, streptomycin $(100 \mu \mathrm{g} / \mathrm{ml})$ and amphotericin B $(2.5 \mu \mathrm{g} / \mathrm{ml})$. The cells were maintained in a humidified atmosphere containing $5 \% \mathrm{CO}_{2}$ at $37^{\circ} \mathrm{C}$. Mouse-adapted influenza virus $\mathrm{A} / \mathrm{Guizhou} / 54 / 89$ (H3N2 subtype) was kindly provided by Dr. S.-I. Tamura (National Institute of Health, Tokyo). The virus was grown in the allantoic cavity of 10-d-old embryonated hen eggs at $34^{\circ} \mathrm{C}$ for $2 \mathrm{~d}$. The allantoic fluid was harvested and clarified at $1000 \times g$ for $20 \mathrm{~min}$, and then resulting supernatant fractions were stored in small portions at $-80^{\circ} \mathrm{C}$ until use.

Deposition of FTTC-Labeled HPC in Lung and Nasal Cavity Female BALB/c mice, 7-weeks-old (Japan SLC Co., Ltd., Hamamatsu, Japan) were used in all experiments. Mice were anesthetized by an intraperitoneal injection of sodium amobarbital $(0.2 \mathrm{ml}$ of a saline solution of $11 \mathrm{mg} / \mathrm{ml}$ ), and then $10 \mu \mathrm{l}$ of $0.2-0.5 \%$ FITC-labeled HPC solution in $10 \mathrm{mM} \mathrm{Na}_{2} \mathrm{CO}_{3}$ /saline was administered intranasally by dropping $5 \mu \mathrm{l}$ of the solution into each nostril with a pipette. The solution was sucked into the 
nostrils by breathing. Five min or $6 \mathrm{~h}$ later, a nasal wash was obtained by washing the nasal cavity of the head with $2 \mathrm{ml}$ of phosphate buffered saline (PBS) containing $0.1 \%$ bovine serum albumin (BSA) and antibiotics. The lungs were excised and homogenized with Polytron ${ }^{\mathrm{TM}}$ PT10-35 (Kinematica $\mathrm{GmbH}$, Littau) in $3 \mathrm{ml}$ of $0.02 \mathrm{M}$ phosphate buffer ( $\mathrm{pH} 7.0)$ containing unlabeled HPC $(20 \mu \mathrm{g} / \mathrm{ml})$, to raise the recovery of FITC-labeled HPC. The homogenate was allowed to stand at $0^{\circ} \mathrm{C}$ for $1 \mathrm{~h}$ and then centrifuged at $2000 \times \mathbf{g}, 4^{\circ} \mathrm{C}$ for $20 \mathrm{~min}$. Acetonitrile $(3 \mathrm{ml})$ was added to the resulting supernatant $(3 \mathrm{ml})$, vortexed and stood for $1 \mathrm{~h}$ at room temperature. The mixture was centrifuged at $2000 \times g, 4^{\circ} \mathrm{C}$ for $20 \mathrm{~min}$. The resulting supernatant and nasal wash were analyzed by HPLC and the deposition of FITC-labeled HPC in lung and nasal cavity were determined.

Analysis of FITC-Labeled HPC with HPLC Sample $(150 \mu \mathrm{l})$ was injected into HPLC column. HPLC was performed on a TSK-GEL G6000PW $\mathrm{XL}_{\mathrm{XL}}$ column $(7.8 \mathrm{~mm}$ i.d. $\times 300 \mathrm{~mm}$, Tosoh) with $0.02 \mathrm{M}$ phosphate buffer $(\mathrm{pH}$ 7.0) as mobile phase and fluorescence was detected at an excitation wavelength of $493 \mathrm{~nm}$ and emission wavelength of $520 \mathrm{~nm}$.

Viscosity Viscosity of HPC and FITC-labeled HPC solutions were measured with an Ubbelohde viscometer at $37^{\circ} \mathrm{C}$.

In Vivo Anti-influenza Virus Activity Mice were anesthetized as described above and then infected by intranasal administration of $10 \mu \mathrm{l}$ of mouse-adapted influenza virus A/Guizhou/54/89 suspension in PBS containing $0.1 \%$ BSA (a $1 / 5000$ suspension of the original virus pool with $10^{4.9} 50 \%$ egg infective dose). F36 was dissolved in $10 \mathrm{mM} \mathrm{Na} \mathrm{CO}_{3} /$ saline containing various concentrations of HPC, and $10 \mu \mathrm{l}$ of the solution was administered to the mouse intranasally. Three $d$ later, a nasal wash was obtained as described above. A bronchoalveolar wash was obtained by injection of $2 \mathrm{ml}$ of a washing solution, twice, into the trachea and lungs which were separated from the body. Serial dilutions of the nasal and broncho-alveolar washes were prepared in EMEM containing $0.2 \% \mathrm{BSA}$, acetyltrypsin $(3 \mu \mathrm{g} / \mathrm{ml})$ and antibiotics, and $100 \mu \mathrm{l}$ of each dilution was added to the confluent monolayers of MDCK cells in the wells of a 96 well culture plate, and then incubated at $37^{\circ} \mathrm{C}$ for $3 \mathrm{~d}$ under a $5 \% \mathrm{CO}_{2}$ atmosphere. Then, the monolayers in the culture plate were separated from the medium, washed with PBS to remove the dead cells resulting from infection of the influenza virus, and the viable cells were determined by a colorimetric method which is based on the in situ reduction of 3-(4,5-dimethyl-thiazol-2-yl)-2,5-diphenyltetrazolium bromide (MTT) by viable cells. ${ }^{12)}$ After discarding the supernatants, $100 \mu \mathrm{l}$ of MTT $(1 \mathrm{mg} / \mathrm{ml})$ in PBS was added and the monolayers were incubated at $37^{\circ} \mathrm{C}$ for $2 \mathrm{~h}$. The resulting formazan precipitate was dissolved with isopropanol containing $0.04 \mathrm{~N} \mathrm{HCl}$ followed by the addition of an equal volume of water, and the absorbance of the solution was determined spectrophotometrically at $570 \mathrm{~nm}$ with a Microplate Reader. The virus titers of nasal and broncho-alveolar washes were expressed as the lowest dilution of the wash which was capable of infecting the MDCK cells by cytopathic effect.
Statistics Comparisons between experimental groups were evaluated by ANOVA followed by Fisher's PLSD procedure. Probability $(p)$ values $<0.05$ were considered significant.

\section{RESULTS}

Viscosity of HPC and FITC-Labeled HPC Viscosity of HPC and FITC-labeled HPC were evaluated with a viscometer at $37^{\circ} \mathrm{C}$. HPC, a mucoadhesive polymer, has concentration dependent viscosity from $0.1 \%$ to $0.5 \%$, and $0.5 \%$ HPC solution showed $8 \mathrm{cP}$ of viscosity (Fig. 1). FITC-labeled HPC also showed potent viscosity equal to that of unlabeled HPC, and $0.5 \%$ FITC-labeled HPC showed $7.5 \mathrm{cP}$ of viscosity. These results indicate that FITC-labeled HPC is appropriate for evaluation of deposition of HPC in lung and nasal cavity.

Deposition of FITC-Labeled HPC in Lung and Nasal Cavity BALB/c mice were intranasally administered various concentrations of FITC-labeled HPC solution $(10 \mu \mathrm{l})$, and $5 \mathrm{~min}$ or $6 \mathrm{~h}$ later, FITC-labeled HPC in the lung and nasal wash were analyzed by HPLC. As shown in Fig. $2 \mathrm{~A}$, at the concentration of $0.5 \%$, less deposition of FITClabeled HPC was observed in the lung. However, 0.2 or $0.3 \%$ solution of FITC-labeled HPC was deposed $5 \mathrm{~min}$ later and retained for $6 \mathrm{~h}$ in the lung. High deposition ratio was also observed at $5 \mathrm{~min}$ by $0.4 \%$ FITC-labeled HPC but had significantly decreased $6 \mathrm{~h}$ after intranasal administration. Deposition ratio of FITC-labeled HPC in nasal wash was almost the same level at each concentration $5 \mathrm{~min}$ after intranasal administration (data not shown), but $6 \mathrm{~h}$ after intranasal administration the deposition ratio was increased depending on its concentration and a tendency for significant difference between $0.2 \%$ and $0.5 \%$ HPC solutions was observed (Fig. 2B).

Effect of HPC on Antiviral Activity of F36 in Vivo The effect of HPC addition to the F36 solution was studied on replication of the $\mathrm{H} 3 \mathrm{~N} 2$ subtype of influenza $\mathrm{A}$ virus in mice.

Mice were infected intranasally by mouse-adapted influenza virus A/Guizhou/54/89 (H3N2) and, $5 \mathrm{~min}$ later, F36 solution $(0.5 \mathrm{mg} / \mathrm{kg})$ containing various concentrations of HPC was administered intranasally. Virus titers in nasal and broncho-alveolar washes were determined at $3 \mathrm{~d}$ after the infection. As shown in Fig. 3, in the absence

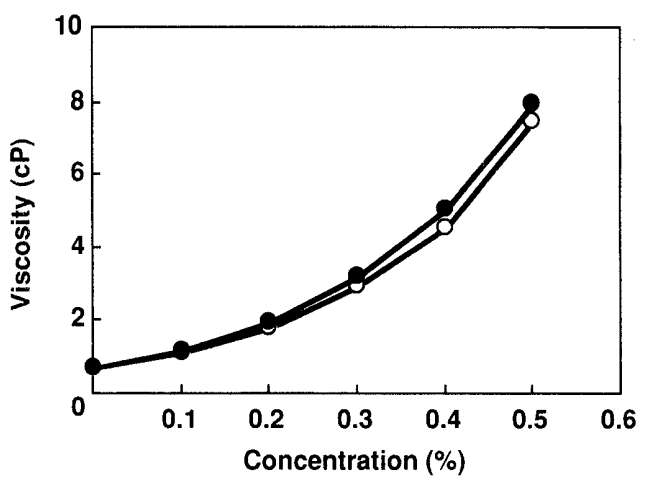

Fig. 1. Viscosity of HPC and FITC-Labeled HPC

Viscosity of various concentrations of HPC $(\bullet)$ and FITC-labeled HPC (O) solutions were evaluated with a Ubbelohde viscometer at $37^{\circ} \mathrm{C}$. 


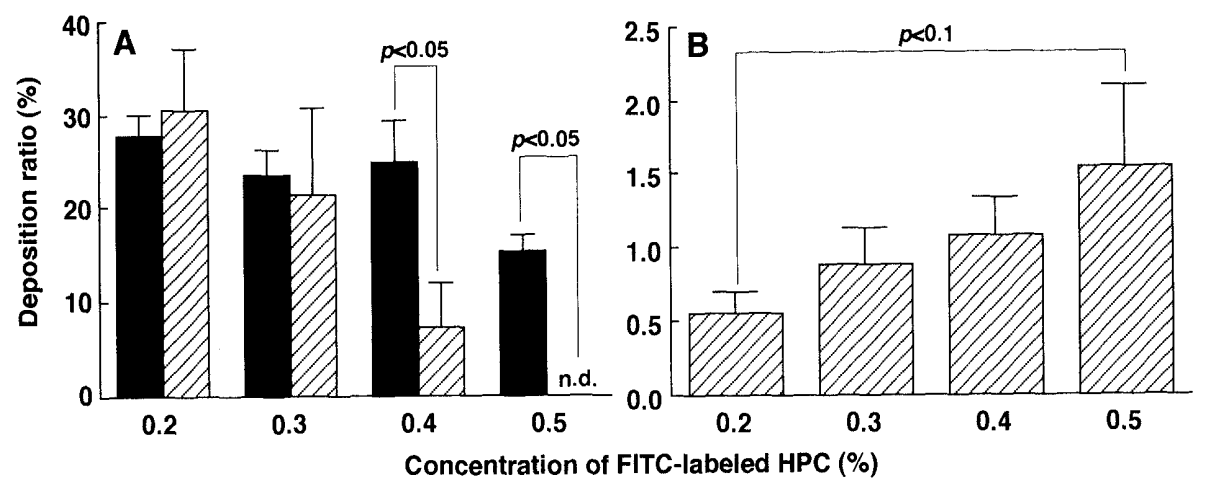

Fig. 2. Effect of Concentration of FITC-Labeled HPC on Its Deposition in the Lung and Nasal Cavity of Mouse

$\mathrm{BALB} / \mathrm{c}$ mice were administered intranasally with FITC-labeled HPC solution in $10 \mathrm{mM} \mathrm{Na}_{2} \mathrm{CO}_{3} /$ saline $(10 \mu$ l). FITC-labeled HPC in the lung (A) and nasal wash (B) were determined by HPLC at $5 \mathrm{~min}(\boldsymbol{E})$ and $6 \mathrm{~h}(\mathbb{E})$ after administration. Values represent mean \pm S.E. $(n=5)$. n.d. $=$ not detectable. Deposition ratio in lung $(\%)=A / B \times 100 . A$ : FITC-labeled HPC in the supernatant of lung homogenate. $B$. FITC-labeled HPC in the supernatant of lung homogenate injected into the trachea of excised lung. Deposition ratio in nasal cavity $(\%)=C / D \times 100$. $C$ : FITC-labeled HPC in nasal wash. $D$ : FITC-labeled HPC inoculated into nostrils of mouse.

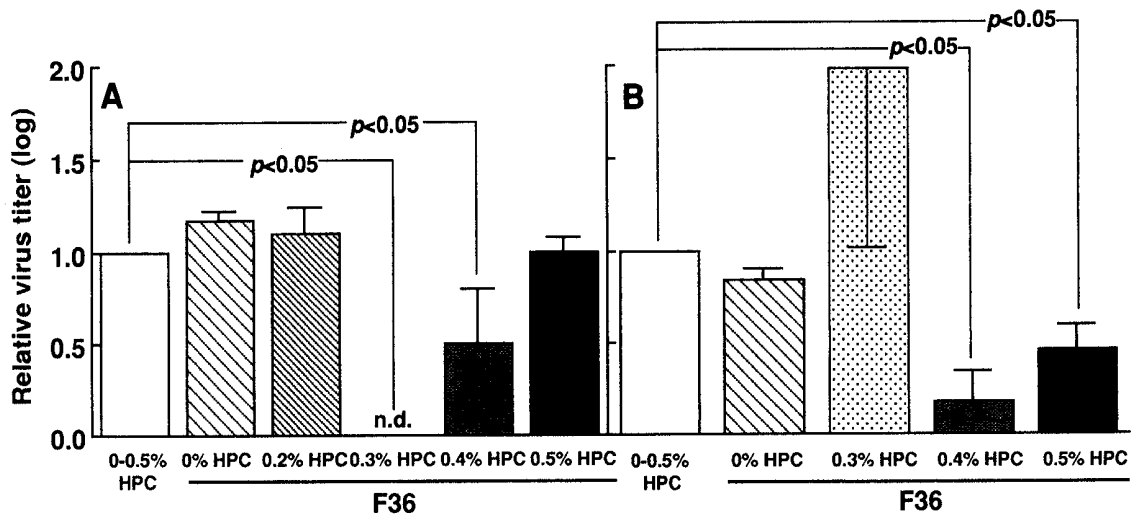

Fig. 3. Effect of HPC on Anti-influenza Virus Activity of F36 in Mice

$\mathrm{BALB} / \mathrm{c}$ mice were intranasally administered $\mathrm{F} 36(0.5 \mathrm{mg} / \mathrm{kg})$ in the presence of various concentrations of HPC at 5 min after intranasal infection of mouse-adapted influenza virus $\mathrm{A} / \mathrm{Guizhou} / 54 / 89$ (H3N2). At $3 \mathrm{~d}$ after infection, virus titers of broncho-alveolar washes (A) and nasal washes (B) were determined. Values represent mean \pm S.E. $(n=3-5)$. n.d. $=$ not detectable.

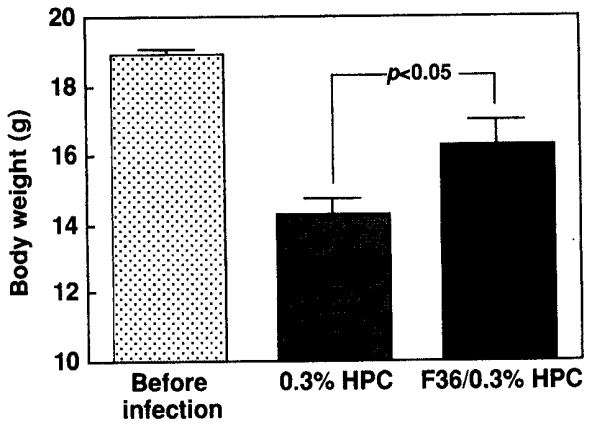

Fig. 4. Effect of F36/0.3\% HPC on the Body Weight of Mice Infected with Influenza Virus

$\mathrm{BALB} / \mathrm{c}$ mice were intranasally administered $\mathrm{F} 36(0.5 \mathrm{mg} / \mathrm{kg})$ in the presence or absence of $0.3 \%$ HPC at $5 \mathrm{~min}$ prior to intranasal inoculation of mouse-adapted influenza virus $\mathrm{A} / \mathrm{Guizhou} / 54 / 89$ (H3N2). Before and $8 \mathrm{~d}$ after infection, body weights of the animals were measured. Values represent mean \pm S.E. $(n=13-30)$.

of HPC, F36 showed no antiviral activity against the $\mathrm{H} 3 \mathrm{~N} 2$ subtype of influenza $A$ virus in either nasal or broncho-alveolar cavities. F36 also did not inhibit proliferation of the virus in the broncho-alveolar wash even in the presence of 0.2 or $0.5 \%$ HPC. However, F36 solution containing 0.3 or $0.4 \% \mathrm{HPC}$ showed significant antiviral activity in broncho-alveolar cavity (Fig. 3A). When 0.4 or $0.5 \%$ HPC solution of F36 was administered, proliferation of the virus was significantly inhibited in nasal wash (Fig.
3B). These results indicate that DDS with HPC enhances the anti-influenza virus activity of F36 in vivo.

Intranasal treatment with $0.5 \mathrm{mg} / \mathrm{kg}$ of $\mathrm{F} 36$ in the presence of $0.3 \%$ HPC significantly improved the body weight loss of mice by mouse-adapted influenza virus A/Guizhou/ $54 / 89$ infection at $8 \mathrm{~d}$ after inoculation (Fig. 4).

\section{DISCUSSION}

Single intranasal administration of F36 $(0.5 \mathrm{mg} / \mathrm{kg})$ showed no antiviral activity against mouse-adapted influenza virus A/Guizhou/54/89 (H3N2 subtype) in the absence of HPC, whereas F36 significantly inhibited the virus proliferation in the mouse lung when administered intranasally 7 times (total $3.5 \mathrm{mg} / \mathrm{kg}$ ) from $18 \mathrm{~h}$ before to $54 \mathrm{~h}$ after virus infection. ${ }^{6}$ Therefore, it was expected that if F36 was kept in nasal and/or broncho-alveolar cavities at high concentration, the flavone might show significant antiviral activity by single administration against mouseadapted influenza virus $\mathrm{A} / \mathrm{Guizhou} / 54 / 89$. HPC is a mucoadhesive polymer and has been used in nasal preparations to retain higher local concentration of drug. ${ }^{7)} \mathrm{HPC}$ has also been used to control the release rate of slightly water soluble drugs. ${ }^{13)}$ Therefore, we studied the effect of HPC on anti-influenza virus activity of F36, which is a kind of slightly water soluble flavonoid. In spite of high deposition 
of $0.2 \% \mathrm{HPC}$ solution in lung, $\mathrm{F} 36$ in $0.2 \% \mathrm{HPC}$ did not show any antiviral activity against the $\mathrm{A} / \mathrm{Guizhou}$ virus in broncho-alveolar cavity. This result indicates that the viscosity of $0.2 \% \mathrm{HPC}$ is not enough to maintain the concentration of F36 in broncho-alveolar cavity. F36 solution containing a low concentration of HPC is thought to spread deeply in the broncho-alveolar cavity because of its low viscosity. However, it is also assumed that the flavone is released from the HPC solution quickly because of that low viscosity, and then clearance of F36 from lung is accelerated. Consequently, the concentration of F36 in lung was immediately reduced to below the level necessary to inhibit replication of the virus. In contrast, $0.3 \%$ HPC deposited in lung for a long period, and F36 solution containing $0.3 \%$ HPC completely inhibited replication of the virus in that organ and improved the body weight loss of mice caused by the virus infection. These results indicate that F36 solution containing $0.3 \%$ HPC delivers to lung and that the HPC maintains the concentration of flavone enough to inhibit replication of the virus. It is expected that $\mathrm{F} 36 / 0.3 \% \mathrm{HPC}$ solution does not distribute in lung as deeply as $0.2 \%$ HPC solution, because viscosity of the $0.3 \%$ HPC solution is lower than the latter. The release rate of the flavone from the $0.3 \%$ HPC solution may be slower than from the $0.2 \%$ HPC solution because of its higher viscosity, however, and consequently adequate concentration of F36 in lung is retained to inhibit proliferation of the influenza virus. A solution of $0.5 \%$ HPC deposited less in lung and a F36 solution containing $0.5 \% \mathrm{HPC}$ did not inhibit the replication of influenza A/Guizhou virus. This may result from the high viscosity of $0.5 \%$ HPC solution which prevents delivery of F36 to broncho-alveolar cavity. Influenza virus suspension in PBS inoculated intranasally may distribute deeply in bronchoalveolar cavity. Therefore, F36/0.5\% HPC solution may not reach the influenza virus proliferating area in this cavity, so that proliferation of the virus is not inhibited. It is also known that ciliary movement is active in the shallow part of broncho-alveolar cavity. Clearance of F36/0.5\% HPC may occur by the ciliary movement to the pharynx from this cavity at $6 \mathrm{~h}$ after administration. In turn, $0.5 \%$ HPC remained in nasal cavity for a long time where this solution of F36 showed significant antiviral activity against $\mathrm{A} /$ Guizhou virus. Our preliminary experiment with a chamber equipped with nitrocellulose membrane (pore size, $0.1 \mathrm{~mm}$ ) also showed that release rate of F36 from $0.5 \%$ HPC solution is slower than that from solution which contains no HPC (data not shown). These results suggest that $\mathrm{F} 36 / 0.5 \% \mathrm{HPC}$ solution remains in the nasal cavity because of its high viscosity and shows antiviral activity.

The deposition ratios of F36 in the nasal and bronchoalveolar cavities were not studied here, because detection of the flavone was difficult in the nasal and bronchoalveolar washes. We will prepare radiolabeled F36 and study the deposition rates of flavone in these respiratory tract cavities in future.

We previously reported that F36 showed potent antiviral activity against $\mathrm{H} 1 \mathrm{~N} 1$ subtype of influenza A virus, mouse-adapted influenza virus $\mathrm{A} / \mathrm{PR} / 8 / 34$, in mice. ${ }^{4)}$ In the present study, F36 also showed significant antiviral activity against $\mathrm{H} 3 \mathrm{~N} 2$ subtype of influenza A virus, mouseadapted influenza virus $\mathrm{A} / \mathrm{Guizhou} / 54 / 89$, by DDS using HPC. These results suggest the possibility that co-administration of F36 with HPC potentiates the antiviral activity of F36 against several subtypes of $\mathrm{A}$ virus in vivo.

Acknowledgments We are grateful to Dr. S.-I. Tamura, National Institute of Health (Tokyo, Japan), for providing mouse-adapted influenza virus A/Guizhou/54/89. We also wish to thank Ms. M. Urata and Mr. K. Fukazawa for their technical assistance.

\section{REFERENCES}

1) Colman P. M., "The Influenza Viruses," ed. by Krung R. M., Plenum Press, New York, 1989, pp. 175-218.

2) Kingsbury D. W., "Virology," ed. by Fields B. N., Knipe D. M., Raven Press, New York, 1990, pp. 1075--1089.

3) Nagai T., Miyaichi Y., Tomimori T., Suzuki Y., Yamada H., Chem. Pharm. Bull., 38, 1329-1332 (1990).

4) Nagai T., Miyaichi Y., Tomimori T., Suzuki Y., Yamada H., Antiviral Res., 19, 207-217 (1992).

5) Nagai T., Moriguchi R., Suzuki Y., Tomimori T., Yamada H., Antiviral Res., 26, 11-25 (1995).

6) Nagai T., Suzuki Y., Tomimori T., Yamada H., Biol. Pharm. Bull., 18, 295-299 (1995).

7) Nagai T., Nishimoto Y., Nambu N., Suzuki Y., Sekine K., J. Controlled Release, 1, 15-22 (1984).

8) Tomimori T., Miyaichi Y., Kizu H., Yakugaku Zasshi, 102, 388-391 (1982).

9) Morita N., Chem. Pharm. Bull., 8, 66-71 (1960).

10) Iinuma M., Tanaka T., Iwashima K., Matsuura S., Yakugaku Zasshi, 104, 691-694 (1984).

11) Kinoshita A., Sakagami M., Sakon K., Makino Y., Fujii T., Abstracts of Papers, The 116th Annual Meeting of Pharmaceutical Society of Japan, Kanazawa, March 1996, Part 4, p. 31.

12) Pauwels R., Balzarini J., Baba M., Snoeck R., Schols D., Herdewijn P., Desmyter J., De Clercq E., J. Virol. Methods, 20, 309-321 (1988).

13) Yuasa H., Takahashi H., Ozeki T., Kanaya Y., Ueno M., Chem. Pharm. Bull., 41, 397-399 (1993). 